\title{
Durability of domestic scroll compressor systems
}

\author{
I. Tzanakis, M. Hadfield \& Z. Khan \\ School of Design Engineering and Computing, \\ Bournemouth University, UK
}

\begin{abstract}
A thorough surface examination of the main components of a scroll compressor after part uses was conducted. This was performed in order to identify the possible tribo-mechanical effects (abrasion, cavitation, erosion etc) which occur on the substrate of these components. Three dimensional interferometer surface scanning and scanning electron microscopy (SEM) were used for surface analyses. Subsequently the parts were used to perform sliding tribological tests using a special purpose built modified microfriction machine to clearly identify their wear and friction mechanisms.

The main interacting material parts of the scroll were identified and used for bench tests. The experimental conditions were adjusted to those of the industrial applications. The critical components for durability were identified on the tip seal and the plate of the scroll compressor. These components are manufactured from high performance fluoroelastomer and high carbon steel materials.

The rational behind these tests is to assess the durability and performance of the scroll compressor system. This specific scroll compressor consists of two involute scrolls; the one orbits eccentrically in respect to the other, compressing various refrigerants. The scroll was under operational conditions for more than 300 hours within a CHP system.

The microscopic and the sliding results showed that cavitation on the steel plate is an issue to be taken into consideration. Two and three body abrasive wear dominates and can considerably affect the durability and the performance of the scroll.
\end{abstract}

Keywords: compressor, scroll, abrasion, cavitation, fluoroelastomer, steel. 


\section{Introduction}

A scroll compressor is an innovative machine which was invented in 1905 by Creux and was used for compressing air or refrigerant. Around the mid 1970s this inefficient technology was interpreted properly and the first working pair of scrolls with very small tolerances was a fact. Since that time the scroll compressor has gained popularity and during the last 10 years it has been the main part of many domestic appliances (CHP systems, air-conditions, heat pumps etc) [1].

A scroll is a device that uses two interleaved spiral shaped scrolls to compress or to expand mainly refrigerants which are used as the working fluid for these systems. In this case it is used as an expander. One of the scrolls is fixed whilst the other orbits eccentrically without rotating, thereby the working fluid is trapped and simultaneously expands into the gas pockets between the scrolls $[2,3]$.

The scroll compressor which was used for this report is a small volumetric positive displacement device and it operates in a high pressure ratio between the suction and the discharge valve. The operation of the scroll expander is based on the organic ranking cycle (ORC). The ORC is similar to the cycle of a conventional steam turbine, except for the fluid that drives the turbine, which is a high molecular mass organic fluid. In this case the working fluid was a hydrocarbon refrigerant. The specific scroll was under operational conditions for more than 300 hundred hours as a main part of a small domestic combine heat and power (CHP) system. The role of this compressor is to expand the working fluid instead of compressing it $[4,5]$.
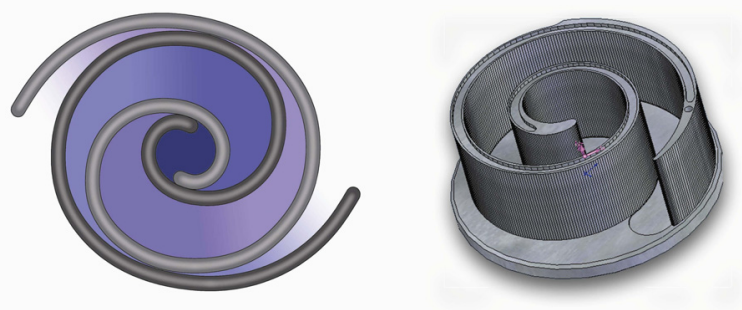

Figure 1: $\quad$ Scroll compressor operation process.

During the operation process of the scroll (fig1), the working fluid after coming through the evaporator and reaching the gas state enters into the central chamber of the scroll at a pressure of about 12 bar and temperature of $150^{\circ} \mathrm{C}$. At the end of a complete cycle of the scroll the working fluid leaves the compressor at a pressure of 2-3 bar and temperature of about $110^{\circ} \mathrm{C}$. The scroll rotates eccentrically with a rotation speed of 3000rpm.

There are many complications regarding the scroll's performance. As reviewed by Cristian Cuevas higher rotation speeds or pressure ratio can steeply increase the working fluid's exhaust temperature which can chemically degrade the lubricant and the working fluid leading the scroll system to a thermally 
mechanical failure. Moreover according to Leonid Paramonov high pressure ratio results to a high start up friction torque while the high pressures will introduce more efficiency losses. Apparently the biggest problem is the leakage of the gas which is responsible for the reduction of the volumetric efficiency of the working fluid. Typically the gap between the bottom or the top plate and the scrolls is around 1 micron $(\mu \mathrm{m})$ across which the leakage is strangled. This may be significantly increased by wear and other tribological effects and it is known that if it reaches around 8 microns $(\mu \mathrm{m})$, the scroll becomes useless [6-8].

The main interactive parts at the leakage points between the bottom plate and the scrolls are the high carbon steel (HCS) plate and the tip seal made by high performance fluoroelastomer (HPF). This is why the experimental wear tests will be focused on the performance of these two materials in order to evaluate the durability of the scroll.

Initially in this study a thorough surface examination of the main components of a scroll compressor was made. The interpretation of their wear mechanisms was completed. Then the wear and the possible cavitation mechanisms were identified while an effort was made to check the tribological behaviour of the actual interacting parts of the scroll, with the use of the special purpose modified pressurised microfriction machine TE 57.

\section{Experimental procedure}

The movement of the involute scrolls of the compressor is eccentric with a $10 \mathrm{~mm}$ diameter at a constant frequency of $50 \mathrm{~Hz}$. In the TE 57 machine, the sample follows a sinusoidal movement as it is produced by an electric rotary motor. The stroke was set at $5 \mathrm{~mm}$ in total and the speed was constant at $25 \mathrm{~Hz}$. This model was thought to approach the scroll's movement. Both movements caused sliding wear. Thus an effective evaluation of the wear effects inside the scroll during its operation can be estimated.

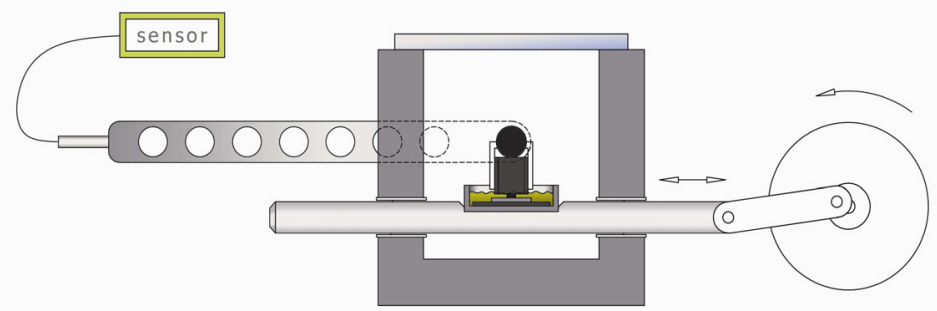

Figure 2: Wear bench test-system schematic.

Figure 2 shows a schematic of the wear bench-test machine. The equipment is based upon a standard set-up from Phoenix Ltd model TE77 micro-friction machine. A modification allows for control of' the environmental conditions 
surrounding the contact to simulate those found within the scroll compressor. The resultant micro-friction machine operates by sliding a lower-plate sample in a reciprocating motion against a fixed sample pin or ball. The plate is mounted in a bath to constrain a lubricant whilst the pin is connected via a feedback mechanism to a transducer to provide friction force feedback and hence friction co-efficient [9].

\section{Experimental methodology}

\subsection{Overview}

The main components of a scroll compressor after part uses were thorough examined. Three different types of microscopes were used. Those were an optical microscope (Olympus), a surface interferometer microscope (ZYGO) and a scanning electronic microscope (SEM). The results that show the wear failure mechanisms of the scroll are focused on the tip seal and the steel plate. Then an effort was made in order to evaluate the wear results and to understand the tribological behaviour of HPF tip seal against the HCS plate.

The tip seal is in a continuous contact with the counterface steel plate during the operation of the scroll. The tip seal reduces the leakage between the different crescent shaped gas pockets of the scroll. Despite the fact that the tip seal has excellent wear behaviour, still the high carbon steel plate is much harder and stronger so that it can cause wear failure to the fluoroelastomer tip seal.

Thus the tip seal and the steel plate were tested in the TE57 pressurised micro friction machine. The operating environment of the micro friction machine was adjusted as closely as possible to that of the scroll's compressor.

\subsection{Chemical properties}

The chemical properties of the steel plate and the tip seal were determined (table 1). Initially the steel sample was etched in a solution of $2 \%$ Nital in order for its grain structure to be determined. Then with the help of an optical emission spectrometer (OES) the steel sample was effectively distinguished in its elements. The steel plate structure comprises of isolated spheroidal carbides in a matrix of tempered martensite.

Table 1: Chemical analysis of the scroll's main interacting components.

\begin{tabular}{|l|l|l|l|l|l|l|l|l|l|}
\hline $\begin{array}{l}\text { Steel } \\
\text { Plate }\end{array}$ & $\% \mathrm{C}$ & $\% \mathrm{Mn}$ & $\% \mathrm{Si}$ & $\% \mathrm{~S}$ & $\% \mathrm{P}$ & $\% \mathrm{Cu}$ & $\% \mathrm{Ni}$ & $\% \mathrm{Cr}$ & $\% \mathrm{Fe}$ \\
\hline $\mathrm{Wt} \%$ & 0.96 & 0.53 & 0.27 & 0.003 & 0.021 & 0.01 & 0.02 & 0.18 & $\mathrm{REM}$ \\
\hline \multicolumn{3}{|c|}{ Tip Seal } & \multicolumn{3}{c|}{$\% \mathrm{~F}$} & \multicolumn{3}{c|}{$\% \mathrm{Si}$} & \multicolumn{3}{c|}{$\% \mathrm{Ca}$} \\
\hline \multicolumn{3}{c|}{96.39} & \multicolumn{3}{c|}{2.54} & \multicolumn{3}{c|}{1.07} \\
\hline
\end{tabular}

The tip seal is a fluoroelastomer in a mixture of fluorine with other chemical elements. The chemical analysis of the fluoroelastomer was made with the use of a scanning electronic microscope (SEM). 


\subsection{Test specimens}

Material test specimens were produced utilising the main parts of the scroll. The steel plate was cut in appropriate testing specimens. Then the specimens were stuck on the surface of other steel samples. The specimens from the tip seal were cut as well and implemented on the surface of enhancement rectangular steel samples. Special holders were constructed to hold the specimens.

The surface finish of the HCS plate was properly measured by the ZYGO interferometer microscope and found to be $\mathrm{Ra}=0.5 \mu \mathrm{m}$. For the HPF samples the surface roughness was measured with the test surf machine using a sliding stylus across the surface. The Ra value was estimated to be $2 \mu \mathrm{m}$. The hardness for the steel plate and for the tip seal is measured with a value of $530 \mathrm{HV}$ and $100 \mathrm{HV}$ respectively.

\subsection{Test conditions}

The test conditions inside the chamber of the TE 57 machine should match those found within the scroll compressor at the contact between the steel plate and the tip seal (table 2). Initially the contact load at the start up conditions of the scroll was estimated and it was found to be around $850 \mathrm{~N}$. This was achieved by measuring the friction torque and the static coefficient of the scroll during the start up conditions. Then with the use of the equation 1 assuming that the torque $\mathrm{T}(\mathrm{Nm})$ is equally distributed across the contact parts, the normal contact load $\mathrm{L}$ (N) was estimated

$$
T=\mu \times L \times r
$$

where $r(m)$ is the radius of the eccentricity and $\mu$ is the dimensionless static coefficient between the tip seal and the steel plate. Then the contact parameters were matched to those on the samples.

Three critical temperatures were chosen for the test processes. The temperature at the start up conditions $\left(40^{\circ} \mathrm{C}\right)$ of the scroll. The temperature at its outlet port $\left(100^{\circ} \mathrm{C}\right)$ where the working fluid leaves the scroll after it expands. The temperature at its inlet $\left(150^{\circ} \mathrm{C}\right)$ port where the working fluid is introduced for expansion into the scroll.

Table 2: $\quad$ Physical parameters for the scroll compressor and the test samples.

\begin{tabular}{|l|c|c|}
\hline Physical Parameter & Scroll Compressor & Test Samples \\
\hline Contact Load $(\mathrm{N})$ & 850 & 40 \\
\hline Contact Area $\left(\mathrm{m}^{2}\right)$ & $2.3 \times 10^{-3}$ & $9 \times 10^{-5}$ \\
\hline Contact Stress $(\mathrm{MPa})$ & 0.37 & 0.4 \\
\hline Surface Velocity $\left(\mathrm{m} \mathrm{s}^{-1}\right)$ & 1.57 & 0.25 \\
\hline
\end{tabular}

\subsection{Test procedure}

The initial tests detailed in Table 3 were conducted using the TE 57 micro friction machine described previously. After the installation of the samples into 
the holders of the TE 57 machine $3 \mathrm{ml}$ of lubricant were introduced into the bath. The lubricant which was used in these experiments is the actual lubricant of the scroll. Is a synthetic oil of a nominal viscosity $170 \mathrm{cSt}$ at $40^{\circ} \mathrm{C}$. The load was set to be $40 \mathrm{~N}$ for all the experiments and the speed was constant at $25 \mathrm{~Hz}$. Each of the tests was carried at a minimum of 4 times and the results were interpreted using the average values of these tests. Then the tests were run for 10 hours. In both the cases of the $100^{\circ} \mathrm{C}$ and the $150^{\circ} \mathrm{C}$ where the data could not provide sufficient results for comparison the tests duration was extended to 30 and 60 hours respectivelly.

Initially an estimation of the sliding friction coefficient was done using the samples into a non-lubricated environment while keeping the same conditions. The coefficient was found to be around 0.11 while after 5 hours was reduced to 0.03 , because the HPF is probably melted. The idea behind it was to produce a reference point of the kinematic friction coefficient value. This will help for a better interpretation of the lubrication performance in all cases.

Table 3: $\quad$ Wear bench test conditions.

\begin{tabular}{|c|c|c|c|}
\hline Number of cases & Test regime & Temperature $(\mathrm{C})$ & Time $(\mathrm{sec})$ \\
\hline 1 & No Lubrication & 25 & 36.000 \\
\hline 2 & Synthetic Oil & 40 & 36.000 \\
\hline 3 & Synthetic Oil & 100 & 36.000 \\
\hline 4 & Synthetic Oil & 150 & 36.000 \\
\hline 5 & Synthetic Oil & 100 & 108.000 \\
\hline 6 & Synthetic Oil & 150 & 216.000 \\
\hline
\end{tabular}

\section{Results and discussion}

\subsection{Surface analysis of the scroll's main parts}

The surface analysis mainly focused on the HCS plate (fig 3). The process which was followed in order for the plate to be thoroughly analysed consisted of the use of the three different microscopes described previously. Moreover the investigation focused on two different regions of the scroll. These are the high pressure region (HP) and the low pressure region (LP).

The first interesting observation that was extracted was the different nature of the wear marks between the high and the low pressure region (fig 4). On the low pressure region the marks are more superficial and not so deep while on the high pressure one the marks are about 3 times wider and around 4 times deeper. This is a rough evidence of what is expected in the experiments with higher condition temperatures. Moreover the wear which is more obvious and prevails not only on those regions but across the whole scroll's plate surface can be determined as a two body abrasive wear. 

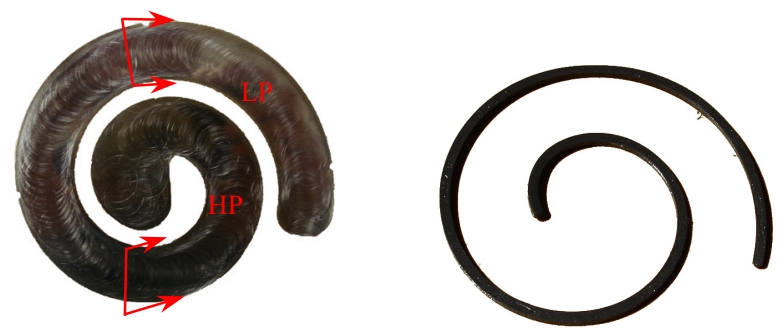

Figure 3: a) Circular wear marks on the steel plate after use 300 hours b) Tip seal.
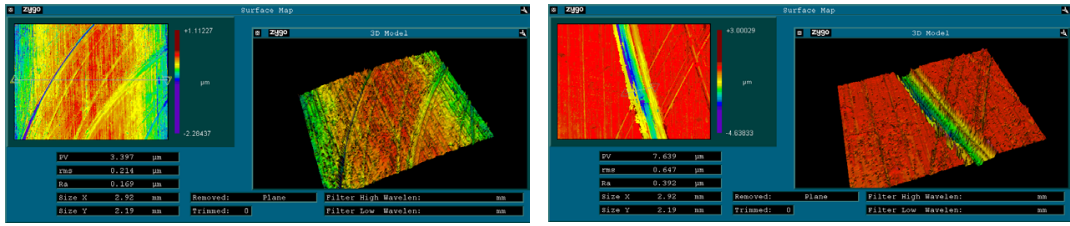

Figure 4: a) Low Pressure Region average depth of the marks $0,5-1 \mu \mathrm{m}-$ b) High Pressure Region average depth of the marks 2-4 $\mu \mathrm{m}$.

Apart from the two body abrasion, cavitation and three body abrasion wear were identified in many areas of the scroll's plate. Characteristically many cavities were found on different spots around the surface of the steel plate which implies the presence of random cavitation effects. On the low pressure region more detailed river marks (fig 5) where detected which were around $2 \mathrm{~mm}$ long. What is more interesting is that they do not follow the path of the wear circular marks but have a totally different direction. The SEM showed that three body abrasion is the clue for these long rivers, let alone the fact that many cavities have been formed around these areas. These cavities, which in some cases may developed by cavitation impact, erode the surface of the steel plate while steel particles are released into the lubricant solution. These particles in their own way now produce three body abrasion during the contact of the two opposite surfaces during the scroll's operation.
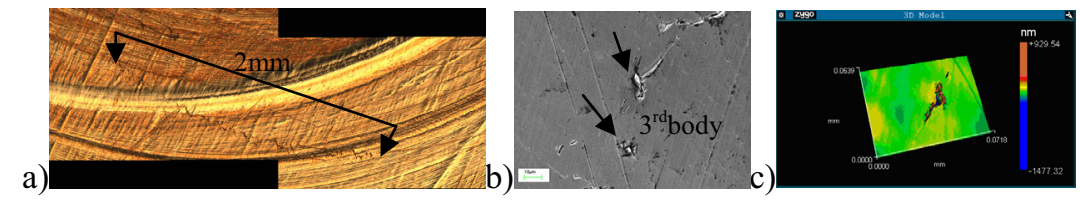

Figure 5: a) The river marks across the steel plate b) Looking at the river marks c) Surface profile of the river marks. 
In addition random points where identified with a cluster of elongated cavities in a much smaller size across many different areas around the scroll. Also evidence of isolated bigger size cavities were spotted at many different points, especially on the high pressure region (fig 6). SEM image shows how destructive the cavity can be while their characteristic geometries were defined with the interferometer microscope.

a)

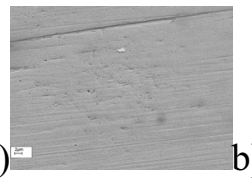

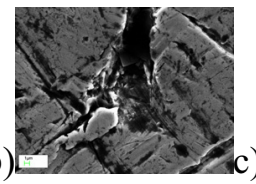
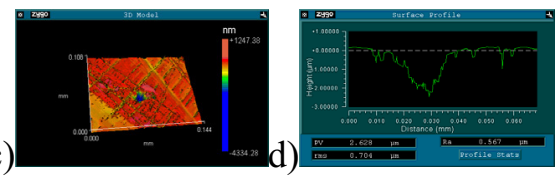

Figure 6:

a) Cluster of cavities

b) Cavity profile

c) 3D-Cavity

d) Surface profile.

Finally at the high pressure region many long river marks were observed but with slightly different nature from the previous one (fig 7). On these marks the effect of the three body abrasion wear is more obvious with a slight suspicion that cavities may have originated from cavitation. The result can be a more severe wear regime.

a)

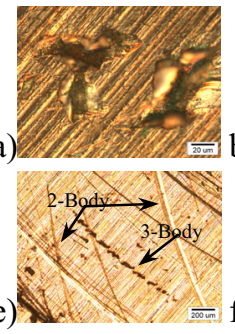

b)

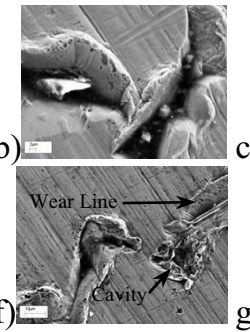

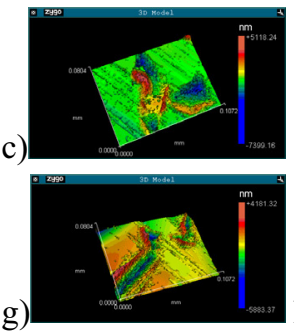

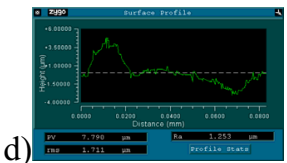

h)

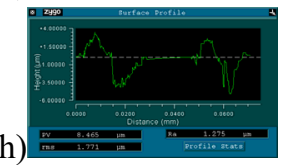

Figure 7: a) 3-Body wear marks b-f) Zooming the marks c-g) 3D profile d-h) Surface profile e) River marks.

For the HPF tip seal not many conclusions were drown from the initial surface investigation. The black colour and the high level of elasticity made the tribological investigation very harsh to be performed. Thus the experiments with the use of the TE 57 machine will show the wear mechanisms of this high efficient material against the steel plate.

\subsection{Test results}

Measurements coming from data acquisition have been used to plot friction coefficient over the time for the different temperature environments (fig 8). The results showed that at the temperature of $40^{\circ} \mathrm{C}$ friction coefficient starts from a value of 0.01 and after a 10 hour running it is stabilized in its minimum value of 
0.006. More or less the same situation was observed in the case of the $100^{\circ} \mathrm{C}$ where the friction coefficient was stabilized at a similar value of 0.005-0.006 after running at douple the time (20 hours). This can easily be comprehended as the samples asperities are at a very close contact for the first couple of hours and then the lubricant shows its very good performance by gradually reducing the friction coefficient and providing excellent hydrodynamic lubrication.

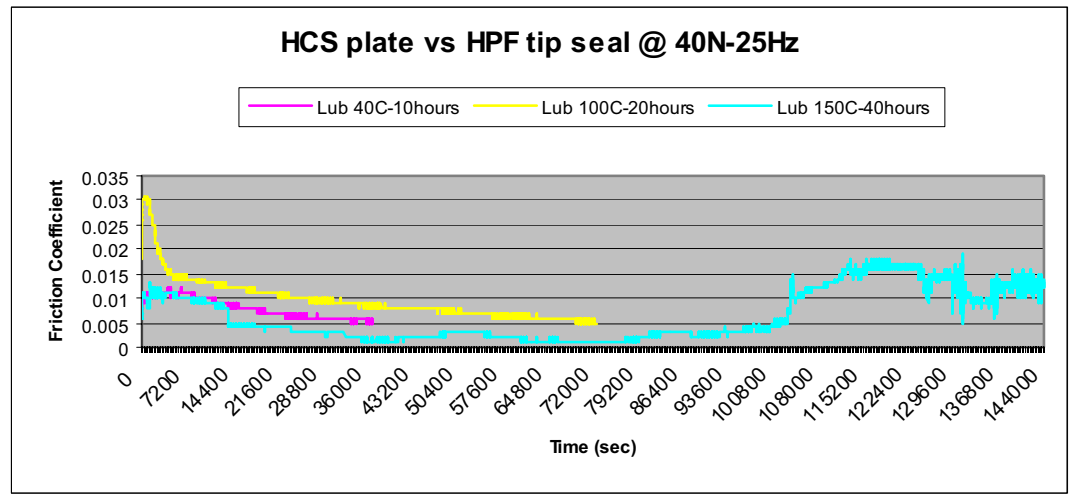

Figure 8: $\quad$ Plot graph of friction coefficient over time for different cases.

In the case of $150^{\circ} \mathrm{C}$ the friction coefficient results are very interesting. What can be highlighted is the steep increase of the friction coefficient after 30 hours of running. During the first 30 hours the behaviour of the lubricant was similar to the previous cases but after that point probably a chemical degradation of the lubricant lead to the rise of the friction coefficient. Then for the remaining hours many irregular fluctuations were observed reaching even the highest friction coefficient value at nearly to 0.02 .

After the evaluation of the samples in all cases, two body wear with evidence of plastic deformation were detected. Moreover a severe three body abrasion wear seriously damaged some parts of the samples. The wear scar dimensions at the plate were measured to provide further comparison between the different cases (fig 9). The wear is becoming more severe as the temperature increases.

Especially three body wear clearly appears in the high temperature cases. The particles are embedded in the surface of the HPF tip seal and they roll across the steel sample creating a series of indentations rather than linear grooves.

Furthermore material from the HPF tip seal was found onto the surface of the steel samples, explaining the adhesive wear mechanism. At lower temperature this phenomenon was more obvious than at the higher one. Probably the mechanical performance of the HPF is improved avoiding the transfer of particles. Another scenario is that the lubricant at these high temperatures can remove more easily the fluoroelastomer particles and clean the steel surface. The adhesion creates mountains with fluoroelastomer material on the surface of the steel with an average peak of $0.05-0.08 \mu \mathrm{m}$. 
Looking at the tip seal samples after the friction/wear tests it can be said that at all occasions the HPF managed to trap the HCS particles and to create in that way a more rough and rigid surface. This could drastically affect the steel plate's structure and durability. Moreover the leakage is increased across the top of the seal. The wear mechanisms on the surface of the fluoroelastomer can be distinguished in 3 regimes: abrasive, adhesive, fatigue. Synoptically presented in the block diagram (fig 10).

a)

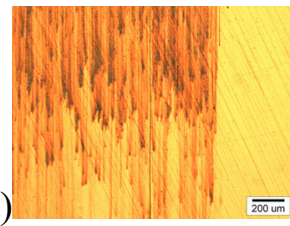

b)

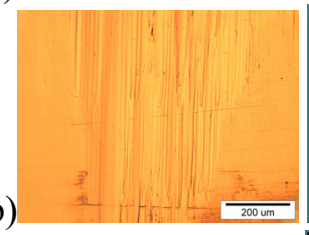

c)
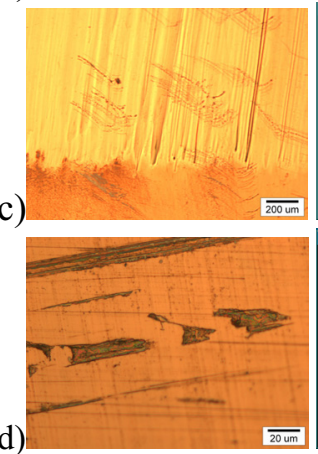

d)

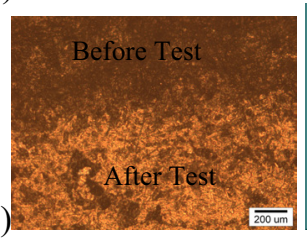

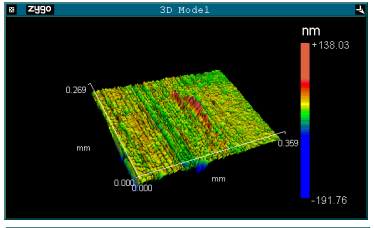
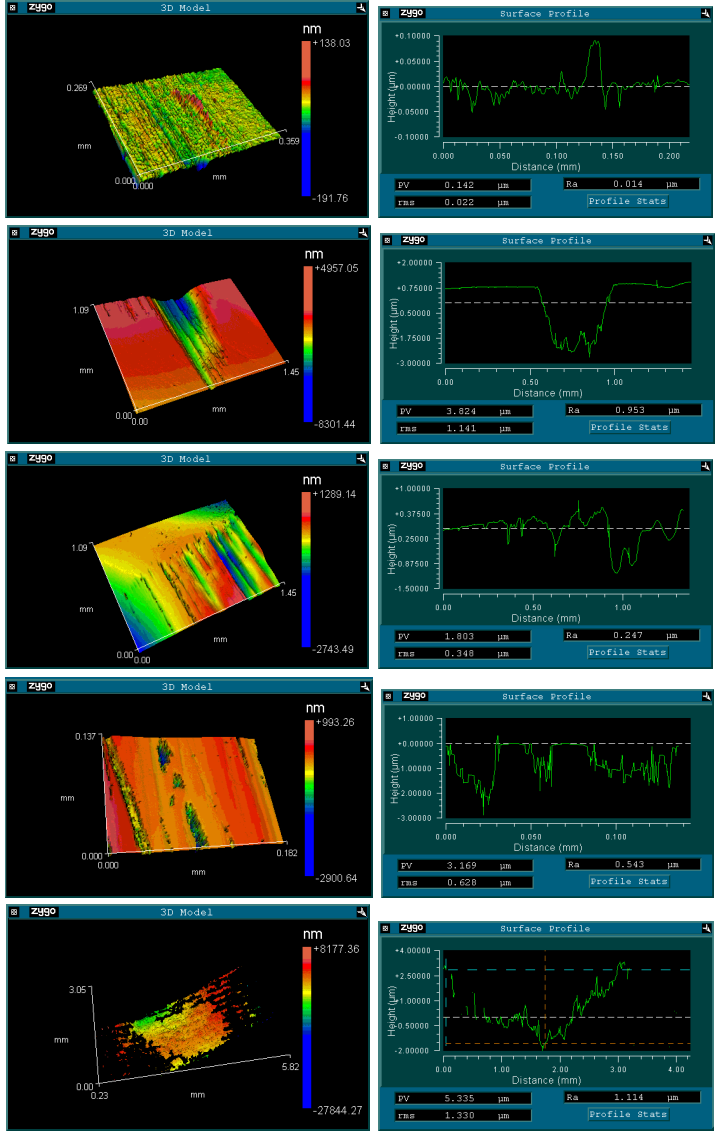

Figure 9: $\quad$ a) $\mathrm{HCS}$ wear at $40^{\circ} \mathrm{C}$-Layers of $\mathrm{HPF}$ with a max height of $0.1 \mu \mathrm{m}$ b) $\mathrm{HCS}$ wear at $100^{\circ} \mathrm{C}$-Max depth $2 \mu \mathrm{m} \mathrm{c}$ ) HCS wear at $150^{\circ} \mathrm{C}$-Max depth $1 \mu \mathrm{m} \mathrm{d}$ ) 3 -Body wear at $100^{\circ} \mathrm{C}$-Max depth $2 \mu \mathrm{m}$ e) $\mathrm{HPF}$ wear at $150^{\circ} \mathrm{C}$-Step of $4 \mu \mathrm{m}$.

The surface analysis of the samples showed that abrasive wear is the one which dominates. In all cases abrasive wear was observed while high deposition of steel particles was found. The penetration of the steel particles onto the surface of the fluoroelastomer affects the sealing performance of the tip seal 
since it cannot properly come in a full contact with the steel plate and effectively seal the gaps.

In addition adhesive wear appeared in many cases. This was expected since the steel samples had a very low roughness creating very smooth blunt asperities edges. Transfer of fluoroelastomer particles were found in all the cases. Finally fatigue wear was evident in some of the tested fluoroelastomer samples.

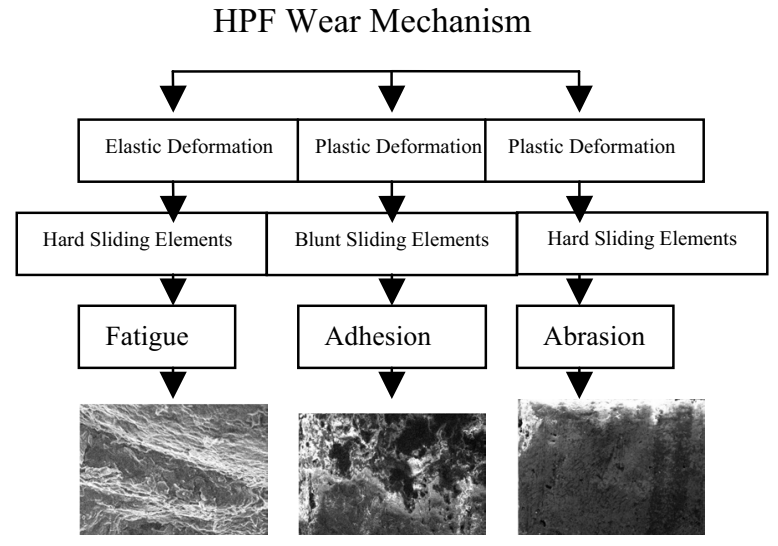

Figure 10: Block diagram of the wear mechanisms found on the tip seal.

After time, both the seal and the counterface steel plate wear out and become thinner. This can seriously affect the performance of the scroll since the leakage can become catastrophic for the efficiency and the life of the scroll.

\section{Conclusions}

Abrasive wear derives from a two body contact in the interface of the tip seal and the steel plate. Moreover severe wear by a three body contact between the two interacting materials using the contaminated particles inside the lubricant/refrigerant mixture was identified.

According to the friction graphs, in the first few hours, the contact between the HCS plate and the HPF tip seal is quite rough. Afterwards the performance of the lubricant is improved, resulting to a lower friction coefficient. Eventually the presence of particles contaminates and degradates the lubricant. This, in turn, causes the enhancement of the friction and the wear rate of the samples especially at high temperatures (e.g. $150^{\circ} \mathrm{C}$ ).

Finally another critical issue which has to be taken into consideration is the cavitation effects during the operation of the scroll. Cavitation can seriously damage the surface of the steel plate by contaminating the lubricant with ferrous particles. Once more, due to the three body wear abrasion the wear between the interacting materials can be increased. 


\section{References}

[1] Wang, B., Li, X. \&Shi, W. Q. 2007. A general geometrical model of scroll compressors based on discretional initial angels of involute. International journal of refrigeration, 28 (958- 966)

[2] Chen, Y., Halm, N.P., Braun, e. \& Groll E.A. 2002. Mathematical modelling of scroll compressors - part I overall scroll compressor modelling. International journal of refrigeration, 25 (751-764)

[3] Tseng C.H. \& Chang, Y.C. 2006. Family design of scroll compressors with optimization. Applied thermal engineering, 26 (1074-1086)

[4] Saleh, B., Koglbauer, G., Wendland, M. \& Fischer, J. 2007. Working fluids for low - temperature organic Ranking Cycles. Energy 32(1210-1221)

[5] Yamamoto, T., Furuhata. T., Arai. N. \& Mori, K. 2007. Design and testing of organic rankine cycle. Energy 26 (239-251)

[6] Cristian Cuevas, Jean Lebrun. 2009. Testing and modelling of a variable speed scroll compressor. Applied thermal engineering, 29 (469-478)

[7] Leonid Paramonov. 2004. PhD Thesis: Simulation-based evaluation of scroll compressors for refrigeration applications. University of Southern Denmark

[8] Howell, P. 2004. Fluid mechanical modelling of scroll compressor. Mathematical institute, 131 (32-56)

[9] Nigel P. Garland, Mark Hadfield. 2005. Tribological Analysis of hydrocarbon refrigerants applied to the hermetic compressor. Tribology International, 38 (732-739) 